\title{
Estudos da exposição às mensagens publicitárias: usos e gratificações
}

\section{Studies of exposure to advertising messages: Uses and Gratifications}

\author{
Raquel M. C. Ferreira
}

Universidade Federal de Sergipe (UFS)

<raquelcarrico@gmail.com>

\section{RESUMO}

Este artigo apresenta uma revisão de literatura dos estudos empíricos desenvolvidos a respeito da atenção seletiva às mensagens propagandísticas. $\mathrm{O}$ objetivo do texto foi demonstrar as motivações para a exposição às mensagens que hoje se caracterizam, principalmente, por sua irrelevância e impertinência, sobretudo em um ambiente tecnológico que as tornam quase sempre intrusivas - razão pela qual são, no geral, ignoradas por seu público. Apresento aqui, portanto, as principais contribuições dos estudos focados no consumo das mensagens publicitárias, destacando os princípios de quatro categorias tidas como as mais relevantes encontradas por meio do estudo: Entretenimento, Obtenção de informações, Integração pessoal e Integração social.

\begin{abstract}
This article presents a literature review from empirical studies developed on selective attention to propagandistic messages. The aim of the text is to present the motivations for exposure to the messages that today are characterized by their irrelevance and impertinence, especially in a technological environment that makes them intrusive: - reason why are generally ignored by their audience. Here I present the main contributions of the studies focused on the consumption of advertising messages. As result, four categories were considered as the most relevant: Entertainment, Information acquisition, Personal and Social integration.
\end{abstract}

Keywords: Advertising. Audience. Uses and Gratifications.

Palavras-chave: Publicidade. Audiência. Usos e Gratificações.

\section{Introdução}

"A irrelevância da mensagem publicitária' nos veículos e nos formatos conhecidos está crescendo com muita rapidez num mundo cada vez mais multimídia, repleto de opções e alternativas que atraem a atenção dos consumidores", disse uma vez Walter Longo em sua página pessoal (Longo, 2015). O publicitário se refere a um processo há muito tempo investigado pela academia, mais precisamente pelos estudos da "Audiência", quando propõe que a "atenção seletiva" dos telespectadores e leitores têm inviabilizado o "negócio da propaganda como a conhecemos".

1 Propaganda e publicidade são aqui entendidas como sinônimas, como indica o Art. $5^{\circ}$ da Lei brasileira $n^{\circ} 4.680$ de 18 junho de 1965, que acusa que propaganda é qualquer forma remunerada de difusão de ideias, mercadorias ou serviços, por parte de um anunciante identificado. 
Não é de hoje que empresários, entidades não governamentais e governamentais têm enfrentado a difícil tarefa de falar com consumidores que não querem ouvir. A publicidade em resposta, tem se tornado mais"ruidosa e mais desagradável (...) e os consumidores não mais aceitam esse tipo de comunicação" (Borum, 2016). O autor é taxativo ao afirmar que até mesmo agarrar esses clientes on-line será impossível. Netflix, Amazon Fire TV e Apple TV já estão livres de anúncios, o YouTube planeja lançar uma versão sem anúncios, e com as versões premium da Pandora e Spotify, a música está livre das mensagens inconvenientes. Fundamental levarmos em conta que, aproximadamente 200 milhões de usuários da Web, usam, em todo o mundo, softwares de bloqueio de anúncios².

A máxima da eficiência da propaganda é mais conteúdo desejável, ou seja, produções relevantes, interessantes e atrativas. De modo genérico, o que podemos considerar como de fato atrativo, interessante e relevante para o consumidor dos anúncios publicitários? Parece fundamental pensarmos sobre as razões que levam aos consumidores a se exporem às mensagens publicitárias.

Uma abordagem útil à questão posta é a dos "usos e gratificações" (U\&G) dos consumidores dessas mensagens. Segundo os princípios do modelo proposto, os conteúdos dos meios de comunicação social podem se constituir em um recurso que satisfaz ou proporciona "usos" para seu consumidor. Este texto visa fornecer uma visão geral da literatura da área bem como os "usos e gratificações" obtidos com o consumo das mensagens propagandísticas. Aqui aponto o estado da arte do consumo da propaganda, desenvolvido sobretudo, nos EUA, Europa e Ásia.

\section{A pesquisa de "usos e gratificações": princípios da exposição seletiva}

O longo percurso dos estudos da audiência dos meios de comunicação social nos mostra um acúmulo de conhecimento estruturado por eixos analíticos dos processos básicos do receptor. Tais processos se referem às respostas que os membros da audiência dão aos meios, como respostas de exposição, de recepção, respostas atitudinais e comportamentais ${ }^{3}$. Segundo Ruótolo (1998),

2 Segundo 2015 global report on ad blocking.

3 O enfoque dos estudos de recepção é norteado pelo processo subjetivo de decodificação das mensagens dos meios pelos receptores. O pressuposto da existência de interpretações que nem sempre vão ao encontro dos significados intrínsecos das mensagens é campo de estudo dessas investigações (o modelo do "interacionismo simbólico" e a pesquisa cultural da recepção são exemplos das investigações interessadas neste processo). Os estudos atitudinais vinculam-se à ideia da eventual capacidade dos meios de influenciar as atitudes da audiência. A atitude é o que determina "certa tendência ao comportamento efetivo", ou seja, uma predisposição à ação efetiva (devido à intrínseca conexão e, muitas vezes, concordância, entre atitude e comportamento, tais estudos são genericamente tratados como pertencentes à literatura dos "efeitos dos meios"). A ideia central do desenvolvimento destas investigações está baseada na hipótese de que se os meios puderem mobilizar com precisão as atitudes 
o propositor desta perspectiva, as análises teóricas passam a eleger um grupo de respostas como sendo seu eixo analítico de estudo porque "não existe uma teoria geral que explique o receptor desde o momento que decide expor-se a um conteúdo de comunicação até as suas últimas consequências comportamentais" (Ruótolo, 1998, p. 160).

As análises teóricas produzidas pela abordagem de Usos e Gratificações se encontram dentro do eixo temático da exposição, e se desenvolveram sobre o interesse do ato de decisão e escolha do receptor em consumir os conteúdos da comunicação social, como a publicidade. U\&G é uma proposição teórica cuja ideia central é a de olhar para "as razões dos mais evidentes apelos dos meios e os vários tipos de conteúdos, perguntando para a audiência, o que ela pensa e aprecia, baseando-se nos hábitos de uso dos meios" (Mcquail, 1983, p. 133).

Essa perspectiva aponta para uma audiência que consome os conteúdos da comunicação social através de suas escolhas com o propósito de satisfazer objetivos pessoais, como se divertir, entender ou resolver um problema. Esta perspectiva considera em sua formulação que o comportamento de exposição seletivaémodeladoporcaracterísticasmultifatoriais,eémais bemcompreendido, pelas motivações que impulsionam o consumo dos conteúdos dos meios.

Essa abordagem se desenvolveu vagarosamente, mas se expandiu de tal forma que não mais falamos em uma teoria de "usos e gratificações", e sim, em um esquema de multiteorias que abordam diversas estratégias de seleção dos conteúdos.

Sinteticamente falando, tal esquema de multiteorias daria conta de uma estrutura teórica complexa, que localiza o processo de gratificação em uma perspectiva global.

das pessoas, poderão subsequentemente, modelar os seus comportamentos. A conduta do receptor dos meios é o foco de análise das perspectivas comportamentais. Ao contrário da perspectiva anterior, essa se centra no comportamento manifesto do receptor, a partir do consumo dos meios. 
- Imagem 1 - Modelo Geral de Usos e Gratificações

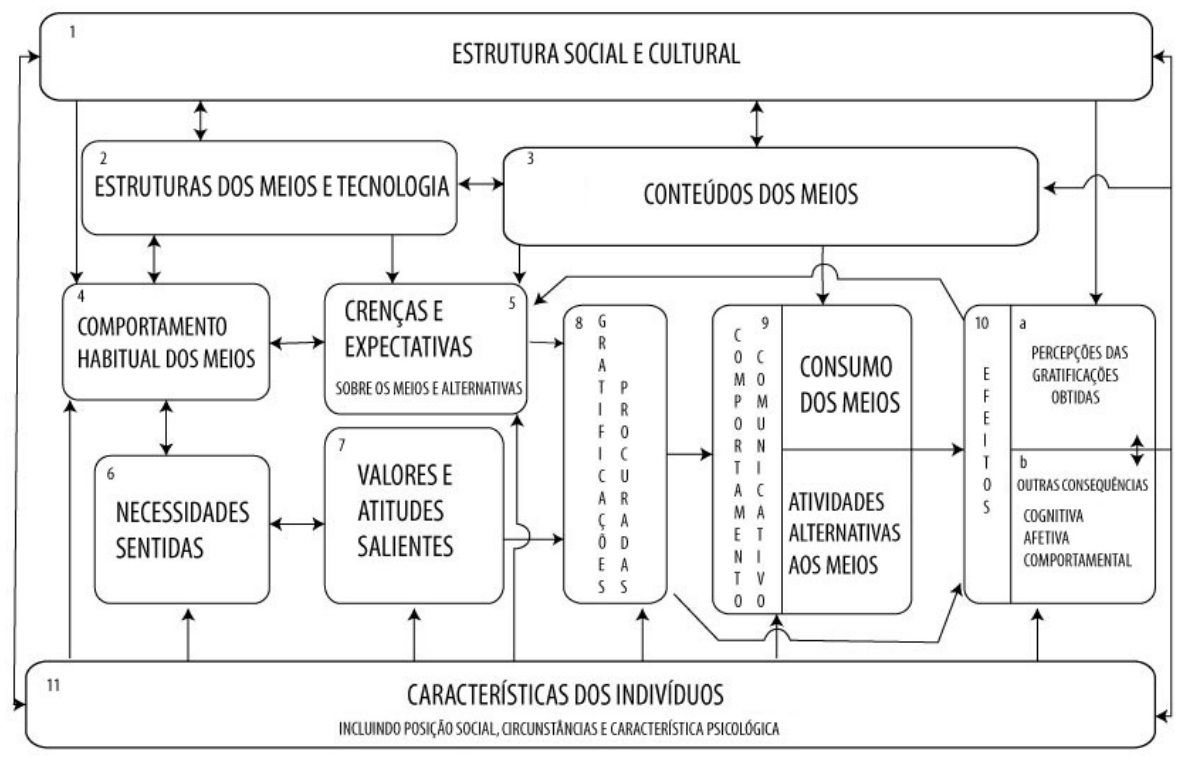

Fonte: Palmgreen, Wenner e Rosengren (1985)

Assim, os consumidores se exporiam às mensagens publicitárias porque elas possuem, ainda que subjetivamente, certa probabilidade de satisfação e uso. As motivações podem ser das mais diversas.

\section{Estudos da propaganda: "usos e gratificações"}

O trabalho de revisão da literatura da área nos apontou doze estudos dedicados às gratificações das mensagens publicitárias, datados de 1983 a 20124. Crosier (1983) descreve alguns tipos de gratificações para o consumo da mensagem publicitária tais como informações sobre o produto, garantias dos atributos dos produtos, identificação das implicações da compra quanto ao serviço pós-compra, entretenimento, experiência vicariante e envolvimento afetivo. Willis (1990) argumenta que consumidores jovens são adeptos a desfrutar da decodificação de mensagens complexas, piadas e referências

4 Para observar o cenário presente das investigações sobre a atenção seletiva do receptor das mensagens publicitárias, busquei textos nas bases repositórias acessadas pelo portal "Periódicos Capes": Scopus (Elsevier), Social Sciences Citation Index (Web of Science), OneFile (GALE), SciVerse ScienceDirect (Elsevier) Wiley Online Library, Science Citation Index Expanded (Web ofScience), Sage Publications (CrossRef), SAGE Journals, Directory of Open Access Journals (DOAJ), Emerald Journals (Emerald Group Publishing), SpringerLink, PsycARTICLES (American Psychological Association). As bases trouxeram 108 periódicos internacionais, me proporcionando a consulta de 499 artigos selecionados através das palavras chaves "Usos e Gratificações" postas em quatro línguas distintas, português, inglês, alemão e espanhol. Dentro da abordagem dos U\&G, selecionei os textos que se dedicaram à mensagem publicitária como escopo, e assim, obtive o total de doze artigos selecionados para esta revisão. 
cruzadas do mundo cultural. Ele também sugere que eles usam a propaganda como referências para integração social.

Lannon (1992) observa que os consumidores esperam da publicidade recompensas estéticas, emocionais e intelectuais, integração pessoal como incremento da credibilidade e posição pessoal, minimização de tensões e conflitos e aquisição e reforço de conhecimentos e de compreensão. Alwitt e Prabhaker (1992) sugerem que as atitudes dos consumidores para a publicidade de TV estão relacionadas com funções hedônicas.

O'Donohoe (1993) em seu estudo aponta que de fato, a propaganda pode oferecer ao seu público vários usos e gratificações como informação sobre produtos e serviços, entretenimento, reafirmação de valores, experiência vicariante, integração social e que nem todas as gratificações se relacionam diretamente aos objetivos mercadológicos da propaganda. Achados de Grant e Donohoe, (2007) sugerem que conveniência, entretenimento, estimulação social, aprendizagem, escapismo e busca de informações de compra foram as principais motivações para exposição às propagandas via SMS.

Consoante com o estudo, os resultados de uma pesquisa com 407 usuários de telefonia móvel em Cingapura mostram que as motivações instrumentais e de diversão afetam não só a probabilidade de exposição às propagandas tipo SMS, mas também, de repasse dos anúncios para outros consumidores. Além do mais, os anúncios de SMS têm maior chance de serem visualizados, aceitos pelos usuários de celulares se estes oferecerem um benefício imediato e entretenimento (Wei, R.; Xiaoming, H.; Pan, J., 2009).

Focando-se em um espectro mais abrangente da propaganda via celular, Peters, Amato e Hollenbeck (2007) descrevem motivos de entretenimento, passatempo, integração social, informação comercial sobre produtos serviços como resultado do estudo exploratório realizado sobre os usos e gratificações da comunicação comercial.

Buenfil (2009) também estuda a publicidade em dispositivos móveis e descobre em levantamento que entretenimento e informação são os aspectos mais destacados para o consumo dessas mensagens. Já Shaheen (2010), em sua tese de doutorado defendida na Alemanha, descreve os motivos para o consumo de propagandas de web sites comerciais. Integração social, entretenimento, conveniência e informação são os achados principais.

Lee e Lee (2011 e 2012) conduziram um estudo sobre a exposição da audiência sobre vídeos de propaganda on-line e descobriram como fator preponderante para a exposição, entretenimento, relaxamento, escapismo, passatempo, interação social. Estes mesmos motivos foram tidos como fatores 
determinantes para a exposição à propaganda on-line em um estudo conduzido e publicado no ano subsequente, agora sobre a lógica do método quantitativo.

$\mathrm{Na}$ dissertação sobre propagandas de vídeos virais, Husted (2012) da Universidade de Missouri, Columbia, mostra que o resultado mais relevante entre os estudantes que enviam ou mostram um vídeo publicitário para outrem é para fazer rir. Proporcionar diversão aos colegas, amigos e familiares foi descrito como razão principal de fazer de um vídeo publicitário um viral.

Tabela 1 - Tipologias de "usos e gratificações" das propagandas 1983-2012

\begin{tabular}{|c|c|c|}
\hline AUTOR E ANO & ENFOQUE & TIPOLOGIAS DE USOS E GRATIFICAÇŐES \\
\hline Crosier (1983) & Propaganda & $\begin{array}{l}\text { Informações, entretenimento, garantias dos } \\
\text { atributos dos produtos, experiência } \\
\text { vicariante e envolvimento afetivo }\end{array}$ \\
\hline Willis (1990) & Propaganda & Entretenimento, jogo, integração social \\
\hline Lannon (1992) & Propaganda & $\begin{array}{l}\text { Prazer estético, entretenimento, escape, } \\
\text { informação, integração pessoal }\end{array}$ \\
\hline $\begin{array}{l}\text { Alwitt e Prabhaker } \\
\text { (1992) }\end{array}$ & $\begin{array}{l}\text { Propaganda } \\
\text { TV }\end{array}$ & $\begin{array}{l}\text { Gerenciamento do humor, integração } \\
\text { pessoal, integração social, vigilância }\end{array}$ \\
\hline O'Donohoe (1993) & Propaganda & $\begin{array}{l}\text { Informaçâo, entretenimento, reafirmação de } \\
\text { valores, identidade pessoal, experiência } \\
\text { vicariante, integração social }\end{array}$ \\
\hline $\begin{array}{l}\text { Grant e Donohoe, } \\
(2007)\end{array}$ & $\begin{array}{l}\text { Propaganda } \\
\text { SMS }\end{array}$ & $\begin{array}{l}\text { Conveniência, entretenimento, estimulação } \\
\text { social, aprendizagem experiencial, } \\
\text { escapismo, e busca de informações de } \\
\text { compra }\end{array}$ \\
\hline $\begin{array}{l}\text { Peters, Amato e } \\
\text { Hollenbeck (2007) }\end{array}$ & $\begin{array}{l}\text { Propaganda } \\
\text { sem fio } \\
\text { (celular) } \\
\end{array}$ & $\begin{array}{l}\text { Entretenimento, passatempo, integração } \\
\text { social, informação comercial sobre produtos } \\
\text { serviços }\end{array}$ \\
\hline Buenfil (2009) & $\begin{array}{l}\text { Propaganda } \\
\text { on-line via } \\
\text { smartphones }\end{array}$ & Entretenimento, informação \\
\hline $\begin{array}{l}\text { Wei, R.; Xiaoming, } \\
\text { H.; Pan, J. (2009) }\end{array}$ & $\begin{array}{l}\text { Propaganda } \\
\text { SMS }\end{array}$ & $\begin{array}{l}\text { Informação, diversão, vantagens imediatas } \\
\text { de compra }\end{array}$ \\
\hline Shaheen (2010) & $\begin{array}{l}\text { Propagandas } \\
\text { on-line/ Web } \\
\text { sites } \\
\text { comerciais }\end{array}$ & $\begin{array}{l}\text { Integração social, entretenimento, } \\
\text { conveniência, informação }\end{array}$ \\
\hline $\begin{array}{l}\text { Lee e Lee (2011 e } \\
\text { 2012) }\end{array}$ & $\begin{array}{l}\text { Vídeos de } \\
\text { propaganda } \\
\text { on-line }\end{array}$ & $\begin{array}{l}\text { Entretenimento, relaxamento, escapismo, } \\
\text { passatempo, integração social, informação }\end{array}$ \\
\hline Husted (2012) & $\begin{array}{l}\text { Propagandas } \\
\text { virais }\end{array}$ & Entretenimento, integração social \\
\hline
\end{tabular}

Fonte: a autora 
De fato, a identificação das motivações que levam os membros da audiência ao processo seletivo de exposição, ao "continuo a assistir" ou "mudo de canal", ignora o anúncio da revista ou jornal, ou "leio-o até seu final", se configura em um processo importante, primordialmente porque esse primeiro comportamento possui ascendência sobre as percepções da comunicação, aceitação dos argumentos da mensagem, memorização, bem como em última instância, sobre os efeitos que podem mobilizar o comportamento da audiência.

Aqui, quaisquer que sejam os efeitos que ocorram, eles são subprodutos das pessoas que usam as mensagens publicitárias (Littlejohn 1982, p. 343). Profissionais da publicidade e acadêmicos entendem que o processo de influência dos comportamentos pela comunicação publicitária atravessa todo um processo que começa pelo desejo de exposição da audiência aos conteúdos, mesmo assim, não se encontra na literatura do tema abordado, o reconhecimento tácito das motivações do público para sua exposição ao conteúdo publicitário.

\section{Propaganda e "usos e gratificações": descrição dos achados principais}

Tendo em vista o fato de que a natureza do consumo das propagandas requer alto interesse do membro da audiência para a sua exposição, a abordagem de U\&G pareceu legítima no fornecimento de compreensão sobre o assunto. Os poucos estudos encontrados demonstram construções diversas sobre os motivos preponderantes para o consumo das propagandas, mas de acordo com este material, as mais importantes e robustas gratificações são entretenimento, obtenção de informação, integração pessoal, integração social. Desse modo, é ponderado adiante, cada uma das gratificações que se mostrou nos estudos levantados, relevante para os consumidores das mensagens publicitárias.

\section{Entretenimento}

Entretenimento é uma categoria motivacional que é aludida mediante termos distintos que designam o mesmo conceito, como distração, brincadeira, escape, prazer estético, jogo, divertimento, riso, apreensão, passatempo, experiência vicariante, alívio de tensão ou tédio. Abordada teoricamente, podemos compreender a categoria como qualquer estímulo que ajude o indivíduo a emular seu estado de humor ou ânimo, ou ainda de excitação, considerado pelo receptor como desejado no momento da sua exposição à mensagem publicitária. 
Zillmann (1985, p. 228) diz que materiais de entretenimento possibilitam considerável excitação ${ }^{5}$ através de estímulos como os do suspense, do mistério, da ação e do humor, manifestando-se no"domínio simpático do sistema nervoso automático, entre outras coisas, e produz reações afetivas".

Isso quer dizer que a atratividade dos conteúdos se conecta com as chances de esses ajudarem os receptores a alterar ou manter estados emocionais ou de excitação inicial apresentado no momento do consumo da mensagem comercial. Aborrecidos e entediados, por exemplo, acabam por se expor aos conteúdos que alteram suas disposições iniciais para um estado mais intenso (das atividades autonômicas destacadamente), com a busca de conteúdos de ação, aventura, animação,comédia,espionagem,terroresuspenseouqualqueroutroestímuloque subjetivamente proporcione fuga ou manutenção do seu estado de humor inicial.

No geral, estressados acabam por escolher conteúdos cujos estímulos são percebidos como neutralizadores dos seus estados de tensão, isso segundo a lógica de que certos conteúdos podem ocasionar um efeito subjetivamente calmante como um conteúdo romântico, fantasioso, musical, ou qualquer um que subjetivamente proporcione a redução do seu nível de excitação (Zillmann, 1985, p. 230). Adicionalmente, membros da audiência com um estado de humor considerado aprazível também podem buscar nos conteúdos publicitários, a sua manutenção.

Apoiado em estudos endocrinológicos, o autor supracitado descreve que uma pessoa que retorna ao lar de um dia de trabalho tenso ou aborrecido acaba por manter um alto nível de excitação inapropriada (Zillmann, 1991, p. 106-107). Também que a "condição condutiva de tal estado é psicológica, podendo ser identificada como uma preocupação cognitiva continuada sobre os eventos responsáveis pela experiência de estresse". A interrupção de tal processo pode ser conduzida por qualquer forma de estimulação recreativa de distração, ocasionando um efeito benéfico de redução e alívio dos níveis de perturbação do membro da audiência. Uma das razões para que tal mudança ocorra, conduzida para níveis considerados como apropriados ou próximos do excelente de excitação (níveis menores de estresse, tédio, entre outros), se encontra na capacidade de as mensagens publicitárias fornecerem estímulos variados que envolvem e absorvem o seu receptor conduzindo-o para outro estado alternativo de humor.

5 O material que entretém pode produzir considerável excitação nos seus receptores. Sua denominação designa-se a uma força unitária que energiza ou intensifica as manifestações corticais e autonômicas (estimulando em destaque, reações afetivas) iniciando, neutralizando ou alterando os estados de humor do receptor (Zillmann, 1991, p. 104-105). 
Neste sentido, O'Donohoe (1993) descreve a publicidade atraente como fornecedora de "fontes particulares de músicas agradáveis, humor, ideias ou imagens interessantes, atores atraentes e histórias engraçadas". Não rara vezes os entrevistados descreveram cantar ou encenar sua propaganda favorita. $\mathrm{O}$ elemento da "novidade" principalmente, pareceu ser fator que entretém e atrai. A autora indica que alguns dos seus entrevistados questionaram, por exemplo, a necessidade de comunicação de algumas marcas já estabelecidas, pois eles se sentiam aborrecidos e entediados com mensagens pesadamente repetitivas. "Anúncios de sabão em pó, são tolerados se há algo novo sobre o produto".

Em uma investigação (Ferreira e Espanha, 2017, no prelo) focada no consumo das propagandas nas mídias digitais por jovens ${ }^{6}$, entretenimento é observado como um elemento altamente surpreendente capaz de envolver o membro da audiência a dispensar sua atenção até o fim da mensagem apresentada. $\mathrm{O}$ formato de Content Marketing ${ }^{7}$, Storytelling ${ }^{8}$ entre outros como o patrocínio deliberado de formatos como séries, documentários e até mesmo filmes foram destacados. A ideia de um formato e conteúdo "fora do padrão" é o que provocaria o efeito "atraente ou interessante" e que pareceu ser o elemento mais admirado entre os conteúdos ditos de "entretenimento" nas mídias digitais, o que vai ao encontro do presuposto da"novidade" posto por O'Donohoe (1993).

Segundo Luo (2002), entretenimento é a gratificação mais relevante para a exposição da audiência à propaganda, enquanto que Mcquail (1983) reforça que o valor do entretenimento das mensagens dos meios de comunicação repousa sobre a sua habilidade de preencher as necessidades do receptor para escape, prazer estético, diversão e/ou alívio emocional.

\section{Obtenção de informações}

Algumas vezes denominado de "vigilância", o uso identificado relacionase a busca dos receptores por informações que os mantenham a par do que

6 O referido estudo não foi incluído na grade dos estudos levantados pois ainda não se encontra publicado.

7 Uma variante da publicidade tradicional. Sua característica é o conteúdo editorial que busca entreter e ou educar, envolve mídia própria (canal), com uma comunidade interativa e cativa em que há possibilidade de interação, um público qualificado que se associa (assina, segue) por livre iniciativa ao canal, mídia, e cujos conteúdos são disponibilizados na rede a depender da cronologia estabelecida pelo produtor do conteúdo.

8 Storytelling é uma estrutura narrativa geralmente ligada à ficção. Nos processos mercadológicos da comunicação, busca-se atribuir significados às marcas, produtos ou processos técnicos em um contexto criativo. A produção de uma atmosfera "emocional" para o potencial consumidor pode estimular envolvimento e simpatia por parte desse último. A marca Coca-Cola, por exemplo, costuma utilizar em suas campanhas elementos motivacionais e aspiracionais, atribuindo valor ao processo de revolução pessoal, da celebração da vida nas datas festivas do calendário oficial ou dos encontros fortuitos o cotidiano. 
acontece no mundo dos lançamentos. É uma espécie de detecção do meio mercadológico, dos últimos fatos e tendências. A exposição à propaganda é posta como o reconhecimento entre a oferta de produtos e serviços e os desejos e necessidades particulares dos membros da audiência.

No trabalho de O'Donohoe (1993), os entrevistados falam sobre publicidade como provendo informações sobre produtos, facilitando assim a escolha, conveniência e identificação de atributos. Informações sobre novos produtos e serviços é uma gratificação que o consumidor da propaganda obtém quando ela se mostra útil, muito embora os potenciais consumidores se mostrassem cientes das suas limitações: uma mensagem publicitária conta uma história, não se desenvolve sobre todos os atributos e detalhes da compra do objeto/serviço em questão.

Questionadaaimportânciadapublicidade,estapareceurelevanteàmedida que comunica produtos e serviços importantes aos consumidores. A publicidade também é compreendida como facilitadora das escolhas de duas formas: 1. Estimulando competição e dando aos potenciais consumidores, mais alternativas de compra. 2. Fazendo com que os membros da audiência se decidam por uma das alternativas ofertadas segundo os argumentos postos na comunicação.

Porque grande parte dos trabalhos aqui expostos são proposições de mensuração das variáveis estudadas, abordadas por estratégias de análise da modelagem de equações estruturais; análises de correlação, análises de regressão e fatorial; estatística descritiva e etc., poucos conceitos terminológicos são explorados a ponto de melhor apresentá-los. Ao recorrer ao trabalho de Ferreira e Espanha (2017, no prelo), é possível colocar que, tanto a informação buscada é tida como interesse sobre $A$. produtos específicos de interesse imediato de consumo, quanto de B. interesse vigilante das "novidades do mercado", para desempenho do papel de consultor ou líder de opinião.

Na primeira situação, a propaganda é o gatilho de informação útil, que faz no geral com que o receptor busque se certificar das melhores opções de compra através de pesquisa on-line. Um anúncio promocional de preços abaixo dos praticados de uma loja de perfumaria ou eletrônicos faz com que a audiência inicie uma busca equiparativa de vantagens entre o anunciante e seus concorrentes para tomada de decisão sobre o comportamento de compra.

No ambiente on-line, duas são as condições modeladoras da exposição nas Redes Sociais: As sugestões algorítmicas e as Consultorias especializadas de quem aprova ou recomenda o produto/ serviço anunciado. Na primeira conjuntura, as mensagens publicitárias vão à procura do potencial consumidor, e este, quando alinhado em termos de interesse ao objeto anunciado, se expõe à propaganda. Na outra versão dessa mesma conjuntura, o usuário da 
web busca reviews especializados de pessoas que têm alguma notoriedade em uma área do saber. Estética, alimentação, moda, entretenimento, eletrônicos, automobilística, etc., acabam por envolver "opiniões" valiosas sobre o consumo de produtos e serviços. A busca desses conteúdos caracterizados inicialmente como "instrutivos", embute o encorajamento da experimentação de produtos e serviços indicados na condição da experiência de um indivíduo destacado.

Tais conteúdos, em sua grande maioria, são patrocinados por marcas, não deixando de ser um modelo ou um post publicitário, com o endosso de pessoas de notório saber. O patrocínio na maioria das vezes não é ignorado pelo público consumidor desses conteúdos, o que não minimiza o poder sugestivo dos bloggers, tubers ou dos canais de personalidades admiradas.

No segundo condicionamento da categoria "obtenção de informação", o receptor da mensagem publicitária não vai em busca de subsídio para um comportamento instrumental de compra, seu desejo é uma variante dessa instrumentalização, ele deseja estar "vigilante sobre as novidades do mercado" para desempenhar um papel de "liderança de opinião". Assim, ao menos a primeira versão desta categoria parece encontrar endosso em outro trabalho investigativo levado a cabo. Infelizmente, não foram encontrados outros estudos qualitativos para a refuta ou reforço do entendimento dos achados aqui expostos.

\section{Integração pessoal}

Com a exposição às mensagens publicitárias, o membro da audiência se apodera da representação de determinados condicionamentos, situaçõeschave, que o faz refletir sobre o consenso das ações e costumes, dos significados sugeridos pela propaganda. A exposição para reflexão, aprendizado ou aconselhamento, tem assim uma finalidade instrumental para o membro da audiência; reforçar ou emular uma crença, uma postura e/ou comportamentos.

O'Donohoe (1993) relata que em muitos discursos de sua investigação foi observado que homens bebiam Guinness para parecerem tão legais quanto Rutger Hauer, o ator caracterizado nos anúncios Guinness. Ela constatou discussões sobre o mérito do Jeans Levis em prestigiar seu usuário em comparação às outras marcas do varejo. Segundo os entrevistados, a Levis tinha estabelecido uma imagem de prêmio que distinguia seus usuários, e desse modo, apenas a difusão de tal valor pela propaganda poderia distinguir os usuários ordinários de calças jeans, dos usuários das marcas especiais.

No trabalho de investigação os adolescentes entrevistados aceitavam "até certo ponto", que eles olham para os homens dos anúncios para ver o que eles usam e como eles se vestem, muito embora, tal situação não resultava 
necessariamente, na tomada de referências para o seu próprio modo de vestir. A ideia geral encontrada no consumo das mensagens publicitárias era tomar como referência apenas o que Ihes parecessem adequado, não somente o aspecto de aquisição de produtos, mas também de personalidade e estilo de vida.

A observação dos significados fornecidos pela publicidade conduz o receptor à apreensão de um novo conhecimento que pode fazê-lo reforçar, ajustar/modelar a si para o incremento da sua posição pessoal. Tal reforço/ ajuste pode refletir-se em um simples comportamento de compra ou em um comportamentoquerevelatraços deumapersonalidadedesejável(Ferreira,2015).

Tais colocações são consistentes com inúmeras evidências que os receptores se dirigem aos conteúdos das propagandas e acabam por emular sua aparência e comportamento segundo o aprendizado de um "modelo" (Bandura, 1977; Donohue, 1975; Loughlin, Donohue e Gudykunst, 1980; Meyer, 1973, citado por Hoffner e Cantor, 1991). Tal comportamento também foi notado por McGuire (citado por Hoffner e Cantor 1991) que relata que a audiência frequentemente adota roupas, estilos e maneirismos percebidos como "modelo a ser seguido".

\section{Integração social}

Utilizar a novidade da mensagem publicitária para interagir com colegas de trabalho, amigos e familiares é um dos propósitos da exposição à mensagem publicitária. O'Donohoe (1993) narra tal uso quando os seus entrevistados explanaram que não era incomum falar com amigos sobre publicidade, muitas vezes acontece de se perguntar aos colegas se eles tinham visto "o novo anúncio" ou "a mais recente" campanha. A autora aponta em sua pesquisa que o uso significativo da publicidade pareceu ser o de gerar "temas de conversa", uma vez queuma peça pareçateradquirido"familiaridade"comgrandeparteda população.

$\mathrm{Na}$ sua perspectiva sobre o caráter social de materiais como os da propaganda, Stephenson (1988, p. 88) identifica as chances de integração social dos receptores quando aponta que as conversas principalmente sobre o que é popular, jogam claramente com um fim de sociabilização. Nesse sentido, as situações mediadas pelo o que é de mais popular na sociedade seriam as condições que suportariam interesses chaves para integração e sociabilização, "fazendo fácil para todos, de qualquer estado, idade, inteligência, classe, cor, conversar uns com os outros dentro e fora de casa" (Stephenson, 1988, p. 89).

A propaganda dessa forma se mostraria efetiva para o propósito de integração social, pois oferece não apenas assunto de conversa com receptores terceiros no momento da emissão dos seus conteúdos, mas também, em 
momentos postergados, sendo os assuntos gerados nestas mensagens, o elo de troca de impressões e experiências.

Também, tais conversas não precisam nem mesmo ser efetivas. A ideia de se ter consciência dos assuntos propagados por conteúdos de alto impacto e de grande popularidade é o suficiente para que o consumidor se sinta participante e potencialmente integrado ao seu meio ou grupo social.

Outros estudos sustentam a existência da categoria motivacional com conteúdos populares da comunicação social, mas não necessariamente com as mensagens publicitárias, como Palmfreen, Wenner e Rosengren (1985), Rubin, (1981; 1985 e 1988), Peters, Amato e Hollenbeck (2007) e Atkin (2008).

Ferreira e Espanha (no prelo, 2017) em seu estudo indutivo abordado pela teoria fundamentada em dados, não obtêm esta categoria motivacional para a exposição às mensagens publicitárias nas mídias digitais. Embora o conceito tenha emergido no estudo aplicado, integração social não se configurou como uma categoria motivacional, mas um resultado natural e não expressivo do processo de interação dos membros da audiência com os conteúdos propagandísticos. Assim, a categoria embora tenha se mostrado consistente nos estudos da propaganda, ainda carece de esclarecimentos quanto a sua natureza relacional (se de fato é uma categoria motivacional, categoria estratégica de interação ou categoria resultante da exposição).

\section{Considerações finais}

A abordagem dos estudos aqui descritos aparentam implicações relevantes para a prática da publicidade. A busca por recompensas estéticas, emocionais e cognitivas requer uma reorientação no processo de planejamento da propaganda, que deve considerar tais elementos na mensagem da propaganda, tornando-a de fato, mais relevante, interessante e impactante.

Do mais, as colocações genéricas aqui postas precisam ser tomadas por grupos específicos de públicos cujos fatores exógenos, interesses, estilos de vida sejam coerentes com o perfil dos consumidores dos produtos e serviços a serem anunciados. Somente tendo em conta estas especificidades é que uma mensagem publicitária poderá efetivamente se tornar relevante e atrativa para cada grupo específico de potenciais consumidores.

Neste contexto, lembremos de Carl Hovland (1966) que sintetizou algumas generalizações do tema da persuasão. Com sua revisão analítica do conjunto de dados sobre os princípios da comunicação que afeta o impacto da comunicação, ele demonstra que as características ótimas das mensagens têm sempre em conta, as características do consumidor em potencial e 
suas predisposições particulares de exposição, interpretação, aceitação dos argumentos, memorização.

Estes dois aspectos, tanto da comunicação quanto da audiência são relevantes, pois em conjunto, representam os elementos constituintes facilitadores ou complicadores do processo persuasivo. Como nos diz Wolf, "persuadir os destinatários é um objetivo possível, se a forma e a organização da mensagem forem adequadas aos fatores pessoais que o destinatário ativa quando consome a mensagem [...]" (Wolf, 1995, p. 31).

No processo de favorecimento da disposição do indivíduo para alcançar a simpatia da marca anunciada, é preciso considerar que o público necessita compreender e aceitar os argumentos da comunicação, mas em primeiro lugar, precisa estar motivado para a exposição até o fim da mensagem, o que nos leva a compreender a importância das recompensas esperadas pelos membros da audiência das mensagens publicitárias.

\section{REFERÊNCIAS}

ALWITT, L. F.; PRABHAKER, P. R. Functional and Belief Dimensions of Attitudes to Television Advertising: Implications for Copytesting. Journal of Advertising Research, p. 30-42, set./out.1992.

ATKIN, Charles. Informational utility and selective exposure to entertainment media. In: ZILLMANN, Dolf; BRYANT, Jennings (Eds.). Selective Exposure to Communication. New York: Routledge, p. 63-92, 2008.

BORUM, Pete. Promotional Marketing. Business Source Complete. 2016. Disponível em: https://vpn2.iscte.pt/+CSCO+00756767633A2F2F7271662E6F2E726F667062 756266672E70627A++/eds/detail/detail?vid=10\&sid=021b7d5c-86d8-49528867-0fe0262e8a52\%40sessionmgr101\&hid=120\&bdata=JkF1dGhUeXBIPWlw LGNvb2tpZSxzaGliLHVpZCZsYW5nPXB0LWJyJnNpdGU9ZWRzLWxpdmUmc2N vcGU9c2I0ZQ\%3d\%3d\#AN=116303514\&db=bth Acesso em: 18 nov. 2016.

BUENFIL,C. Publicidad en Dispositivos Móviles:aspectos que determinan su viabilidade. Razón y Palabra, v. 14, n. 68, maio/jun., 2009. Disponível em: http://www. redalyc.org/articulo.oa?id=199520297021 Acesso em: 8 mar. 2016.

CROSIER, K. Towards a Praxiology of Advertising. International Journal of Advertising, v. 2, p. 215-321, 1983.

FERREIRA, Raquel Marques Carriço. Telenovelas Brasileiras e Portuguesas: padrões de audiência e consumo. Aracaju: Edise, 2015.

. ESPANHA, Rita. Exposição às mensagens publicitárias: uma perspectiva dos jovens portugueses nas mídias digitais. (No prelo), 2017. 
FERGUSON, D. A.; PERSE, E. M. The world wide web as a functional alternative to television. Journal of Broadcasting \& Electronic Media, n. 44, v. 2, p. 155174, 2000. Disponível em: http://dx.doi.org/10.1207/s15506878jobem4402_1 Acesso em: 8 jan. 2017.

GRANT, I.; DONOHOE, S. Why young consumers are not open to mobile marketing communication. International Journal of Advertising, v. 26, n. 2, p. 223-246, 2007.

HOFFNER, C.; CANTOR, J. Perceiving and responding to Mass media Characters In: BRYANT, Jennings; ZILLMANN Dolf. Responding to the screen: reception and reaction processes. New Jersey: Lawrence Publishers, p. 63-102, 1991.

HOVLAND, Carl. Efeitos dos meios de Comunicação. In: STEINBERG, Charles. Meios de Comunicação de Massa. São Paulo: Cultrix, 1966. p. 561-609.

HUSTEAD, Arron D. Viral Video Advertisements: uses and gratifications research. Columbia: Master of Arts at Faculty of the Graduate School at the University of Missouri, 2012.

LANNON, J. Asking the Right Questions: What Do People Do with Advertinsing? Revista Admap, p. 11-19, mar. 1992. Disponível em: https://www.warc.com/ Security/Paywall/?OriginalURL=\%2fSubscriberContent\%2fArticle\%2fAsking_ the_right_questions_what_do_people_do_with_advertising\%2f1820 Acesso em: 23 maio 2017.

LEE, Joonghwa; LEE, Hyunmin. Factors influencing the intention to watch online video advertising. Cyberpsychology, Behavior and Social Networking, v. 14, n. 10, p. 619-624, 2011.

Motivations and access characteristics Canonical correlation analysis of online video advertising viewing. New Media Society, v. 14, n. 8, p. 1358-1374, 2012. Disponível em: http://nms.sagepub.com/content/14/8/1358 Acesso em: 22 jun. 2016.

LITTLEJOHN, Stephen W. Fundamentos teóricos da comunicação humana. Rio de Janeiro: Zahar, 1982.

LONGO, Walter. A Luta pela Atenção. 2015. Disponível em: http://walterlongo.com. br/palestras/A\%20Luta\%20pela\%20Atencao_pal.html. Acesso em: 22 fev. 2017.

LUO, X. Uses \& gratification theory \& e-consumer behaviours: a structural equation modelling study. Journal of Interactive Advertising, v. 2, n. 2, p. 34-41, 2002.

MCQUAIL, D. Mass communication theory. London: Sage, 1983.

O'DONOHOE, S. Advertising Uses and Gratifications. European Journal of Marketing, v. 28, n. 8/9, p. 52-55, 1993. 
PALMGREEN, Philip;WENNER, Lawrence; ROSENGREN, E. Uses Gratifications Research: The Past ten years. In: ROSEGREN, Erik; WENNER, Lawrence R. (Eds.) Beverly Hills: Sage Publications, 1985.

PALMGREEN, Philip. (Eds.). Media Gratifications Research. Beverly Hills: Sage Publications, p. 11-37, 1985.

PETERS, C.; AMATO, C. H.; HOLLENBECK, C. R. An Exploratory Investigation of Consumers: Perceptions of Wireless Advertising. International Journal of Advertising. v. 36, n. 4, p. 129-145, 2007.

RUBIN, A. M. A multivariate Analysis of 60 Minutes Viewing Motivations. Journalism Quarterly, v. 58, n. 2, p. 529-534, 1981.

. Uses of daytime television soap operas by college students. Journal of Broadcasting and Electronic Media, v. 29, n. 3, p. 241-258, 1985.

. Media uses and effects: a uses-and-gratifications perspective. In: BRYANT, Jennings; ZILLMANN, Dolf. Media effects: Advances in theory and research. Washington DC: Kent State University, 1988.

RUÓTOLO, A. C. F. Audiência e recepção: perspectivas. Comunicação e Sociedade, UMESP/São Bernardo do Campo, n. 30, p.159-170, 1998.

SHAHEEN, Abd El-Basit Ahmed Hashem Mahmoud Abdullah. Uses and gratifications of online advertising a comparative study between germany and egypt. Alemanha: Technical University of Ilmenau, 2010.

STEPHENSON, W. The play theory of mass communication. New Brunswick/NJ: Transaction Books, 1988.

WEI, R.; XIAOMING, H.; PAN, J. Examining user behavioral response to SMS ads: Implications for the evolution of the mobile phone as a bona-fide médium. Telematics and Informatics, n. 27, p. 32-14, 2009.

WILLIS, P. Common Culture. Open University Press, Milton Keynes, 1990.

WOLF, Mauro. Teorias da comunicação. Tradução de Maria Jorge Vilar de Figueredo. 4. ed. Lisboa: Presença, 1995.

ZILLMANN, Dolf. The Experimental Exploration of Gratifications from Media Entertainment. In: ROSEGREN, Erik; WENNER, Lawrence; PALMGREEN, Philip. (Eds.). Media Gratifications Research. Beverly Hills: Sage Publications, p. 225239, 1985.

- Television Viewing and Physiological Arousal. In: BRYANT, Jennings; ZILLMANN Dolf. Responding to the Screen: reception and reaction processes. New Jersey: Lawrence Publishers, p. 103-134, 1991. 
Recebido em: 20/4/2017

Aceito em: 10/5/2107

Dados da autora:

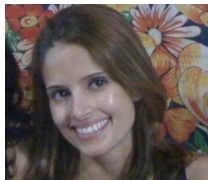

Raquel M C Ferreira | raquelcarrico@gmail.com

Doutorado - Universidade Nova de Lisboa (2011) e mestrado - Universidade Metodista de São Paulo

(2003). Professora Adjunta na Universidade Federal de Sergipe no curso de Publicidade e Propaganda e no

PPGCOM.

Universidade Federal de Sergipe (UFS)

Cidade Universitária Professor José Aloísio de Campos

Av. Marechal Rondon, $\mathrm{s} / \mathrm{n}^{\circ}$ - Jardim Rosa Elze

49100-000 - São Cristóvão (SE) - Brasil 